\title{
MODIFIED APPROACHES FOR CALCULATION OF EFFECTIVE LENGTH FACTOR OF FRAMES
}

\author{
Y.Y. Chen ${ }^{1}$ and G.H. Chuan ${ }^{2, *}$ \\ ${ }^{I}$ Professor, State Key Laboratory for Disaster Reduction in Civil Engineering, Tongji University, Shanghai, China \\ ${ }^{2}$ M. D. Candidate, College of Civil Engineering, Tongji University, Shanghai, China. \\ *(Corresponding author: E-mail: 1130335ChuanGH@tongji.edu.cn)
}

Received: 10 August 2013; Revised: 2 March 2014; Accepted: 11 April 2014

\begin{abstract}
As a crucial factor for stability calculation of frames, the effective length factor is generally determined by the traditional approaches in most current design codes, but some assumptions imposed do not reflect the real frame buckling behaviors. In this paper modified approaches are proposed based on the change of some unreasonable assumptions of the traditional approaches mainly in two aspects. Firstly, the premise that all frame columns buckle simultaneously is changed into an individual column buckling mode in braced frames, or story buckling mode in both braced and unbraced frames. Secondly, actual distribution of axial forces of columns is taken into account, so that the stability functions of columns may not be identical. Moreover, approximate formulas for calculation of the effective length factor are obtained based on the modified approaches, by which a series of numerical analysis is carried out. Numerical analysis results demonstrate that the modified approaches improve the accuracy well compared with the traditional ones.
\end{abstract}

Keywords: Steel structure, Frame, Buckle, Effective length factor, Critical load, Modified approaches

\section{INTRODUCTION}

The concept of effective length factor is instructive for buckling analysis of braced and unbraced axially loaded frames in design, especially for the regular frames because of the simplicity. The determination of effective length factor in codes of American, Australian and China is derived from buckling equations by traditional approaches (AISC [1], SAC [2], GB50017-2003 [3]). However, traditional approaches are based on assumptions of idealized conditions, which seldom exist in real structures. These assumptions are given as follows (AISC [1], Kuhn and Lundgren [4], Chen and Lui [5]):

1. Behavior is purely elastic.

2. All members have constant cross section.

3. All columns in the frame buckle simultaneously.

4. For columns in braced frames, the nodal rotations of columns in every other story are equal in magnitude and opposite in direction.

5. For columns in unbraced frames, the nodal rotations of columns in every other story are equal in magnitude and the same direction.

6. The stiffness parameter $l \sqrt{P / E I}$ of all columns is equal, indicating that stability functions for all columns are identical, where $l, P$ and $E I$ are the story height, column axial force and column flexural rigidity respectively.

7. No significant axial compression force exists in the girders.

Assumptions 3 5 show an important concept of traditional approaches that the global buckling of entire system is equal to the buckling of all columns in the frame. However, in the real situation, individual column buckling in the braced frame and single or several stories buckling in the braced or unbraced frame are more common. Assumption 6 comes to the conclusion that effective length factor is independent of axial load distribution, which is quite different from the reality (Bridge and Fraser [6]). In addition, when the column stiffness parameters are not identical, the errors caused by traditional approaches are significant (Kuhn and Lundgren [4]). 
Much effort has been made to improve traditional approaches. Bridge and Fraser [6] modified the calculation of parameter $G$ in traditional approaches. Essa [7] accounted for the effects of boundary conditions at the far ends of columns above and below the corresponding column. The boundary conditions may be rigid, hinged, or fixed. Chen et al. [8-9] considered semi-rigid beam-column joints, which expanded the scope of traditional approaches. Tong and Wang [10] abandoned assumptions 4 and 5 of traditional approaches. Their method is extended to multi-span with multi-story frames by using consolidation method. However, all the mentioned modifications were based on the premise that all columns in the whole frame buckle simultaneously.

This paper modifies traditional approaches in two aspects. First, the assumption that all columns of the entire frame system buckle together is not adopted and assumptions in traditional approaches about nodal rotations of columns are excluded. The second is that the different distribution of axial forces on columns is considered, which results in that effective length factor is not independent of load distribution. Based on the two modifications, the modified approaches are proposed.

Considering that the instability deformation of unbraced frame has the character of story buckling (Yura [11]), the story-buckling method is used. By the method, it is assumed that the buckling resistance of the story is approximately equal to the sum of the buckling resistance of all columns (Yura [11], White and Hajjar [12], Xu and Liu [13], Choi and Yoo [14]).

\section{THEORETICAL ANALYSIS OF BUCKLING OF FRAMES}

\subsection{Slope-deflection Equations Considering the Effect of Axial Force}

Figure 1 shows an axially compressed-bent member. The slope-deflection equations of the member are given as (Kuhn and Lundgren [4], Galambos and Surovek [15]):

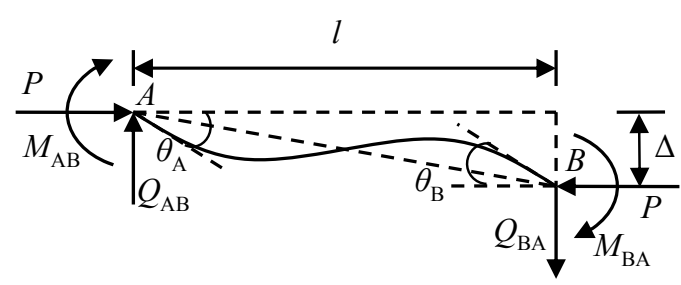

Figure 1. Axial Compression-bending Member

$M_{\mathrm{AB}}=\operatorname{si} \theta_{\mathrm{A}}+c i \theta_{\mathrm{B}}-(s+c) i \rho$

$M_{\mathrm{BA}}=\operatorname{si} \theta_{\mathrm{B}}+c i \theta_{\mathrm{A}}-(s+c) i \rho$

$Q_{\mathrm{AB}}=Q_{\mathrm{BA}}=-(s+c) i\left(\theta_{\mathrm{A}}+\theta_{\mathrm{B}}\right) / l+\left[2(s+c)-\phi^{2}\right] i \rho / l$

where $i=E I / l$ is the span flexural rigidity, $\rho=\Delta / l$ is the relative drift of the member corresponding to the lateral displacement $\Delta, s$ and $c$ are stability functions of the member. Noting the Euler critical $\operatorname{load} P_{\mathrm{E}}=\pi^{2} E I / l^{2}$, then

$\phi=\pi \sqrt{P / P_{\mathrm{E}}}$ 


$$
\begin{aligned}
& s=\frac{\phi(\sin \phi-\phi \cos \phi)}{2-2 \cos \phi-\phi \sin \phi} \\
& c=\frac{\phi(\phi-\sin \phi)}{2-2 \cos \phi-\phi \sin \phi}
\end{aligned}
$$

\subsection{Buckling Analysis of Braced Frames}

The modified model is shown in Figure 2. The assumptions adopted for this model are:

1. The interaction of the story for buckling check and the upper and lower stories is considered, and the effect of other stories is incorporated equivalently with elastic rotational restraints $k_{1}$ and $k_{2}$.

2. At buckling, the end rotations of beams in the story are of equal magnitude but the opposite direction.

3. Axial forces in beams are neglected.

4. Actual forces of the upper and lower columns are considered, and the force of column in the story for buckling check is variable.

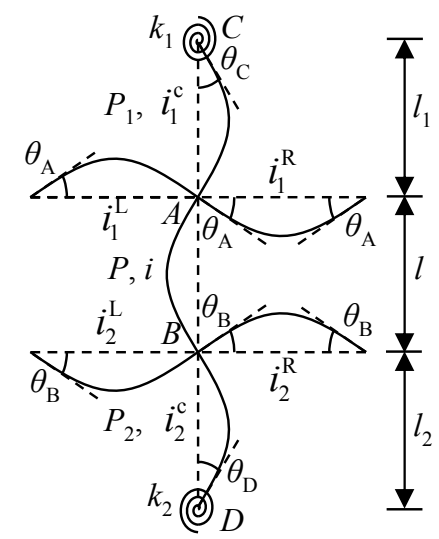

Figure 2. Model for the Braced Frame

Assumption 1 excludes the premise in traditional approaches that the nodal rotations of columns in every other story are equal, and as an alternative, elastic rotational restraints are considered for the effect of other stories. Assumption 4 excludes the previous premise that stability functions for all columns are identical, so that it is in more accordance with the buckling behavior of real structures.

By the slope-deflection equations of axially compressed-bent members, the equilibrium equation of moment for node $C$ is

$s_{1} i_{1}^{\mathrm{c}} \theta_{\mathrm{C}}+c_{1} i_{1}^{\mathrm{c}} \theta_{\mathrm{A}}+k_{1} \theta_{\mathrm{C}}=0$

where $s_{1}$ and $c_{1}$ are stability functions of the upper column.

Then $\theta_{\mathrm{C}}$ is given by

$\theta_{\mathrm{C}}=-\frac{c_{1}}{k_{1} / i_{1}^{\mathrm{c}}+s_{1}} \theta_{\mathrm{A}}$ 
Moments at the bottom end of the upper column and the top end of the corresponding column in the story for buckling check are

$M_{\mathrm{AC}}=s_{1} i_{1}^{\mathrm{c}} \theta_{\mathrm{A}}+c_{1} i_{1}^{\mathrm{c}} \theta_{\mathrm{C}}$

$M_{\mathrm{AB}}=\operatorname{si} \theta_{\mathrm{A}}+\operatorname{ci} \theta_{\mathrm{B}}$

where $s$ and $c$ are stability functions of the corresponding column.

The equilibrium equation of moment for node $A$ is

$M_{\mathrm{AC}}+M_{\mathrm{AB}}+2\left(i_{1}^{\mathrm{L}}+i_{1}^{\mathrm{R}}\right) \theta_{\mathrm{A}}=0$

Substituting Eq. 4 and 5 into Eq. 6, the following equation is obtained

$\left(s+2 W_{1}\right) \theta_{\mathrm{A}}+c \theta_{\mathrm{B}}=0$

Analogously, for node $B$ the following equation can be obtained

$c \theta_{\mathrm{A}}+\left(s+2 W_{2}\right) \theta_{\mathrm{B}}=0$

where $W_{j}=\frac{i_{j}^{\mathrm{L}}+i_{j}^{\mathrm{R}}}{i}+\frac{s_{j}^{2}-c_{j}^{2}+s_{j} k_{j} / i_{j}^{\mathrm{c}}}{2\left(k_{j} / i_{j}^{\mathrm{c}}+s_{j}\right)} \frac{i_{j}^{\mathrm{c}}}{i},(j=1,2)$,

and $s_{2}$ and $c_{2}$ are stability functions of the lower column.

At buckling, $\theta_{\mathrm{A}}$ and $\theta_{\mathrm{B}}$ are not all zeros. By Eq. 7 and 8 , this condition can be written as

$\left|\begin{array}{cc}s+2 W_{1} & c \\ c & s+2 W_{2}\end{array}\right|=0$

By Eq. 2a, effective length factor of the column can be expressed as $K=\pi / \phi$.

So Eq. 10 can be expressed as

$\frac{\pi}{K}\left[\left(\frac{\pi}{K}\right)^{2}+2\left(W_{1}+W_{2}\right)-4 W_{1} W_{2}\right] \sin \frac{\pi}{K}-2\left[\left(W_{1}+W_{2}\right)\left(\frac{\pi}{K}\right)^{2}+4 W_{1} W_{2}\right] \cos \frac{\pi}{K}+8 W_{1} W_{2}=0$

According to Assumption 4, $W_{1}$ and $W_{2}$ in Eq. 11 are known, and only effective length factor of the corresponding column is unknown. It is found that Eq. 11 is formally consistent with the buckling equation of braced frames obtained from traditional approaches, so effective length factor can be determined by alignment chart (AISC [1], SAC [2]), or by the following approximate analysis solution whose form is consistent with traditional approaches' (CM [16], Dumonteil [17-18])

$K \approx \frac{0.64 W_{1} W_{2}+1.4\left(W_{1}+W_{2}\right)+3}{1.28 W_{1} W_{2}+2\left(W_{1}+W_{2}\right)+3}$ 
In Eq. 12, when $W_{1}<0$ or $W_{2}<0$, setting $W_{1}=W_{2}=0$. It is a conservative solution either when the corresponding column unbuckles or buckles, where the former case is obvious. While the corresponding column buckles, the effective length factor is always smaller than 1 (Dumonteil [17-18]), hence setting $W_{1}=0$ and $W_{2}=0$ indicates $K=1$ and guarantees the conservatism of the result.

Effective length factor expressed in Eq. 12 is related to axial load distributions in columns according to Eq. 9. However effective length factor obtained from traditional approaches is independent of load distribution.

For different beam end conditions, adjustments are required. According to structural mechanics, when the far end of the beam is hinged or rigid, the span flexural rigidity should be multiplied by correction factor 1.5 or 2 respectively. When the near end of the beam is hinged, the span flexural rigidity of the beam is zero.

\subsection{Buckling Analysis of Unbraced Frames}

The modified model is shown in Figure 3. The assumptions 1, 3 and 4 adopted for the modified model are as the same as those specified for braced frames stated in above section, while assumption 2 is changed as follows: at buckling, the end rotations of beams in the same story are of equal magnitude and the same direction. And an extra assumption is supplemented as that: shear forces of columns in all stories are taken as zeros.

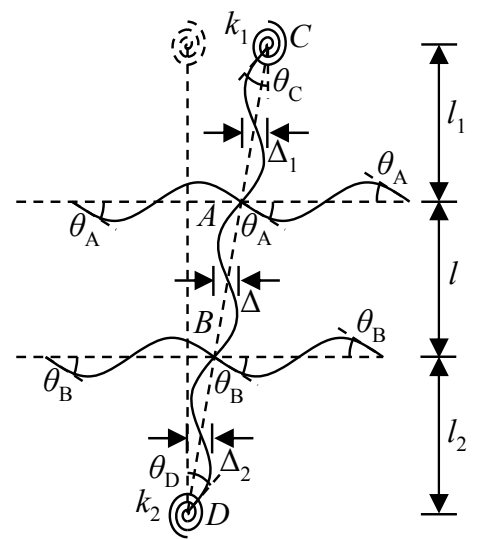

Figure 3. Model for the Unbraced Frame

The modified approaches exclude the premise in traditional approaches that all the story drifts are equal, so it is more rational in practice.

By the slope-deflection equations of axially compressed-bent members, the equilibrium equation of moment for node $C$ is

$s_{1} i_{1}^{\mathrm{c}} \theta_{\mathrm{C}}+c_{1} i_{1}^{\mathrm{c}} \theta_{\mathrm{A}}-\left(s_{1}+c_{1}\right) i_{1}^{\mathrm{c}} \rho_{1}+k_{1} \theta_{\mathrm{C}}=0$

where $\rho_{1}=\Delta_{1} / l_{1}$ is the relative drift of the upper story.

By the extra assumption, the shear force of the upper column is taken as zero, which can be expressed as 
$Q_{1}=-\left(s_{1}+c_{1}\right) i_{1}^{\mathrm{c}}\left(\theta_{\mathrm{C}}+\theta_{\mathrm{A}}\right) / l_{1}+\left[2\left(s_{1}+c_{1}\right)-\phi_{1}^{2}\right] i_{1}^{\mathrm{c}} \rho_{1} / l_{1}=0$

By Eq. 13 and 14, solutions can be given by

$$
\begin{aligned}
& \theta_{\mathrm{C}}=\frac{\left(s_{1}+c_{1}\right)^{2}-\left[2\left(s_{1}+c_{1}\right)-\phi_{1}^{2}\right] c_{1}}{\left(k_{1} / i_{1}^{\mathrm{c}}+s_{1}\right)\left[2\left(s_{1}+c_{1}\right)-\phi_{1}^{2}\right]-\left(s_{1}+c_{1}\right)^{2}} \theta_{\mathrm{A}} \\
& \rho_{1}=\frac{\left(s_{1}+c_{1}\right)\left(k_{1} / i_{1}^{\mathrm{c}}+s_{1}-c_{1}\right)}{\left(k_{1} / i_{1}^{\mathrm{c}}+s_{1}\right)\left[2\left(s_{1}+c_{1}\right)-\phi_{1}^{2}\right]-\left(s_{1}+c_{1}\right)^{2}} \theta_{\mathrm{A}}
\end{aligned}
$$

Moments at the bottom end of the upper column and the top end of the corresponding column are

$M_{\mathrm{AC}}=s_{1} i_{1}^{\mathrm{c}} \theta_{\mathrm{A}}+c_{1} i_{1}^{\mathrm{c}} \theta_{\mathrm{C}}-\left(s_{1}+c_{1}\right) i_{1}^{\mathrm{c}} \rho_{1}$

$M_{\mathrm{AB}}=s i \theta_{\mathrm{A}}+c i \theta_{\mathrm{B}}-(s+c) i \rho$

where $\rho=\Delta / l$ is the relative drift of the story for buckling check.

The equilibrium equation of moment for node $A$ is

$M_{\mathrm{AC}}+M_{\mathrm{AB}}+6\left(i_{1}^{\mathrm{L}}+i_{1}^{\mathrm{R}}\right) \theta_{\mathrm{A}}=0$

Substituting Eq. 15 and 16 into Eq. 17, the following equation is obtained

$\left(s+6 T_{1}\right) \theta_{\mathrm{A}}+c \theta_{\mathrm{B}}-(s+c) \rho=0$

Analogously, for node $B$ the following equation can be obtained

$c \theta_{\mathrm{A}}+\left(s+6 T_{2}\right) \theta_{\mathrm{B}}-(s+c) \rho=0$

where $T_{j}=\frac{i_{j}^{\mathrm{L}}+i_{j}^{\mathrm{R}}}{i}+\frac{\left(s_{j}^{2}-c_{j}^{2}-s_{j} \phi_{j}^{2}\right) k_{j} / i_{j}^{\mathrm{c}}-\left(s_{j}^{2}-c_{j}^{2}\right) \phi_{j}^{2}}{6\left\{\left(k_{j} / i_{j}^{\mathrm{c}}+s_{j}\right)\left[2\left(s_{j}+c_{j}\right)-\phi_{j}^{2}\right]-\left(s_{j}+c_{j}\right)^{2}\right\}} \frac{i_{j}^{\mathrm{c}}}{i},(j=1,2)$.

The shear force of the corresponding column is taken as zero, that is

$$
Q=-(s+c) i\left(\theta_{\mathrm{A}}+\theta_{\mathrm{B}}\right) / l+\left[2(s+c)-\phi^{2}\right] i \rho / l=0
$$

At buckling, $\theta_{\mathrm{A}}, \theta_{\mathrm{B}}$ and $\rho$ are not all zeros, so Eq. 18, 19 and 21 can be written as

$$
\left|\begin{array}{ccc}
s+6 T_{1} & c & -(s+c) \\
c & s+6 T_{2} & -(s+c) \\
-(s+c) & -(s+c) & 2(s+c)-\phi^{2}
\end{array}\right|=0
$$

Eq. 22 can be expressed as 


$$
\left[36 T_{1} T_{2}-\left(\frac{\pi}{K}\right)^{2}\right] \sin \frac{\pi}{K}+6 \frac{\pi}{K}\left(T_{1}+T_{2}\right) \cos \frac{\pi}{K}=0
$$

As stated earlier, effective length factor can be determined by alignment chart (AISC [1], SAC [2]), or by the following approximate analysis solution (CM [16], Dumonteil [17-18], Tong and Wang [10])

$$
K \approx \sqrt{\frac{7.5 T_{1} T_{2}+4\left(T_{1}+T_{2}\right)+1.52}{7.5 T_{1} T_{2}+T_{1}+T_{2}}}
$$

In Eq. 24 , when $T_{1}<0$ or $T_{2}<0$, set $T_{1}=T_{2}=0.0001$, where 0.0001 is a very small number. When the corresponding column buckles, its effective length factor ranges from 1 to $+\infty$ (Dumonteil [17-18]). Thus setting $T_{1}=T_{2}=0.0001$ indicates $K=87$, which can be regarded as an infinite number.

Effective length factor expressed in Eq. 24 is also related to axial load distributions in columns as the situation of Eq. 12.

According to structural mechanics, when the far end of the beam is hinged or rigid, the span flexural rigidity should be multiplied by correction factor 0.5 or $2 / 3$ respectively. When the near end of the beam is hinged, the span flexural rigidity of the beam is zero.

\subsection{Elastic Rotational Restraints $k_{1}$ and $k_{2}$}

Elastic rotational restraints $k_{1}$ and $k_{2}$ represent the effect of boundary condition provided by other stories, however, it might be complex to solve these factors. Therefore, the following simple method is proposed.

Firstly to consider rotational restraint $k_{1}$ for braced frames. Figure 4 shows the column and beams connecting to node $C$. For beams, end rotations are assumed to be coincident with Assumption 2 stated in Section 2.3. For the column, the far end is considered to be hinged conservatively. To avoid over conservative concerning in derivation, the axial force is neglected when calculating the stiffness of the column. Based on those assumptions, $k_{1}$ can be written as

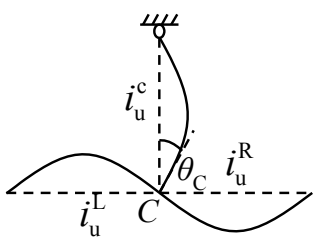

Figure 4. Model for Calculation of $k_{1}$

$k_{1}=2\left(i_{\mathrm{u}}^{\mathrm{L}}+i_{\mathrm{u}}^{\mathrm{R}}\right)+3 i_{\mathrm{u}}^{\mathrm{c}}$

For the rotational restraints $k_{2}$, the column and beams connecting to node $D$ in Figure 2 can be similarly removed from the frame, and using index "d" in physical quantities. Analogously, $k_{2}$ is given by

$k_{2}=2\left(i_{\mathrm{d}}^{\mathrm{L}}+i_{\mathrm{d}}^{\mathrm{R}}\right)+3 i_{\mathrm{d}}^{\mathrm{c}}$

For unbraced frames, rotational restraints $k_{1}$ and $k_{2}$ can be also analogously written as 


$$
\begin{aligned}
& k_{1}=6\left(i_{\mathrm{u}}^{\mathrm{L}}+i_{\mathrm{u}}^{\mathrm{R}}\right)+3 i_{\mathrm{u}}^{\mathrm{c}} \\
& k_{2}=6\left(i_{\mathrm{d}}^{\mathrm{L}}+i_{\mathrm{d}}^{\mathrm{R}}\right)+3 i_{\mathrm{d}}^{\mathrm{c}}
\end{aligned}
$$

For different end conditions of beams, adjustments of span flexural rigidity of beams are required in Eq. 25 and 26. Correction factors are stated in Section 2.2 and Section 2.3.

Of cause, different calculating methods of rotational restraints $k_{1}$ and $k_{2}$ have effect on the accuracy of the model herein, but proposed method here is simple and practical without big error as shown by following demonstrations for validation.

\section{MODEL VALIDATION}

\section{1 $\quad$ Frame Models}

FEM solutions are considered as real solutions to assess the accuracy of the proposed effective length factors; meanwhile errors of the critical load proposed by this study and traditional approaches are compared. In order to provide a comprehensive comparison, four kinds of Frame Types are designed. For the computation of each model, both the buckling configuration in braced frame without side sway and the one in unbraced frame with side sway are supposed.

In the group of Frame Type 1, there are 16 frame models with the various spans and stories as shown in Table 1. All the span flexural rigidity of columns and beams is equal, set as $i_{\mathrm{b}}=i_{\mathrm{c}}=i$. All story heights and column spaces are equal $l$. Figure 5a shows the distribution of axial loads on columns. Load distributions in each story are the same, and the loads on external columns are half of those on other columns.

In the group of Frame Type 2, there are also 16 frame models generally same as Frame Type 1, except that the span flexural rigidity of columns and beams is equal respectively, set as $i_{\mathrm{b}}=0.8 i$ and $i_{\mathrm{c}}=i$.

Table 1. Models of Frame Type 1 and 2

\begin{tabular}{|c|c|c|c|c|c|c|c|c|c|}
\hline Number of spans & \multicolumn{7}{|c|}{ Number of stories } \\
\hline 3 & 1 & 3 & 5 & 10 & 15 & 20 & 25 & 30 \\
\hline 8 & 1 & 3 & 5 & 10 & 15 & 20 & 25 & 30 \\
\hline
\end{tabular}

Traditional approaches have a key assumption that stability functions for all columns are identical (Kuhn and Lundgren [4], Chen and Lui [5]). In order to compare the two kinds of approaches when this assumption is satisfied, Frame Type 3 is designed. This type contains 3-span and 8-span with 10 -story frames. Loads at the top of every column including the external column are set equal as shown in Figure 5b, and the column span flexural rigidity reduces from the $1^{\text {st }}$ floor to the $10^{\text {th }}$ floor to make stability functions of all columns identical, and the span flexural rigidity of columns and beams in the same story is supposed to be the same. The column span flexural rigidity of the first story is noted $i$.

In contrast to Frame Type 1 3 in which all column-beam joints are fixed and all column spaces are identical, other 6 frame models classified as Frame Type 4 are designed as shown in Figure 6. In those frame models, unequal spans and hinged end conditions of columns and beams are supposed, so that the validity of the modified approaches can be further checked. Each frame model has 3 
spans and 5 stories. Frame model 1 and 2 are with unequal spans. In Frame model 3 and 4, a part of beams are with hinged connection to columns. Frame model 5 and 6 contain leaning columns. All frames in Type 4 have the same story height $l$ and the same section of beams and columns. Load distributions are the same as Frame Type 1 2 as shown in Figure 5a. Braced and unbraced buckling modes are considered for each frame model.

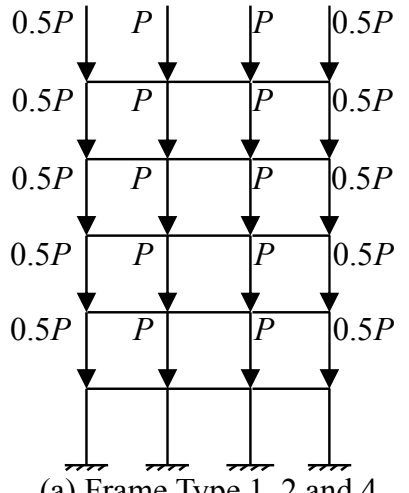

(a) Frame Type 1, 2 and 4

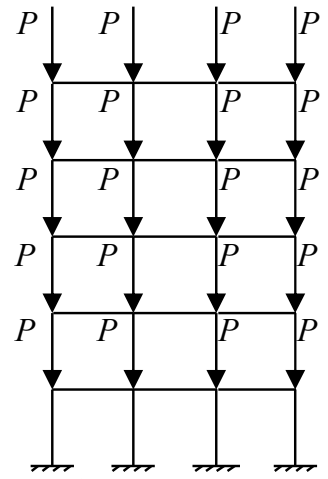

(b) Frame Type 3

Figure 5. Load Distribution for Frame Type 1 4

\subsection{The Determination of Critical Load}

\subsubsection{Calculation of critical load using modified approaches}

In order to solve the critical load of the frame, the following iteration is adopted:

1. Setting an initial load $P_{0}$, and calculating critical forces of all columns.

2. Determining and correcting critical story loads by utilizing critical forces of columns. For braced frames, critical force of each story is the minimum one of critical forces of columns in the story. For unbraced frames, story critical forces can be obtained by story-buckling method (Yura [11], White and Hajjar [12], Xu and Liu [13], Choi and Yoo [14]). For the load distribution in Frame Type 1, 2 and 4, the story critical force is given by

$$
P_{\mathrm{s}_{-} \mathrm{cr}}^{j}=\frac{1}{N} \sum_{m=1}^{N+1} P_{\mathrm{c}_{-} \mathrm{cr}, m}^{j},
$$

and for the load distribution pattern in Frame Type 3

$$
P_{\mathrm{s}_{-} \mathrm{cr}}^{j}=\frac{1}{N+1} \sum_{m=1}^{N+1} P_{\mathrm{c}_{-} \mathrm{cr}, m}^{j}
$$

where $N$ is the number of spans, $P_{\text {s_cr }}^{j}$ is the critical force of the $j$-th story, and $P_{\mathrm{c}_{-} \text {r }, m}^{j}$ is the critical force of the $m$-th column in the $j$-th story.

3. Determining critical load of the frame. Every story critical force corresponds to a critical load $P_{\mathrm{cr}}{ }^{\prime}$ of the frame. It is clear that the minimum one noted as $P_{\mathrm{cr}}$ is the critical load of the frame under the distribution of $P_{0}$.

4. If $P_{0}=P_{\mathrm{cr}}$, that is the critical load of the frame; if $P_{0}>P_{\mathrm{cr}}$ or $P_{0}<P_{\mathrm{cr}}$, reducing or increasing $P_{0}$ to calculate $P_{\text {cr }}$ again by step 1 to 4 until $P_{0}=P_{\text {cr. }}$ 


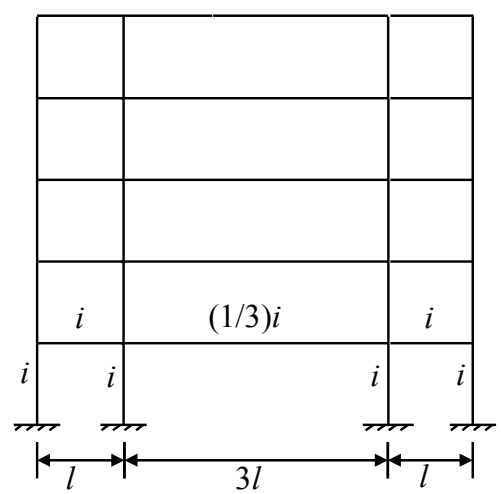

(a) Frame 1

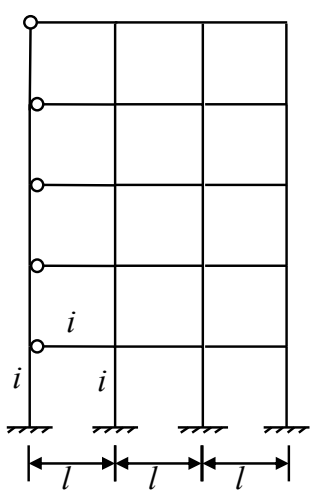

(c) Frame 3

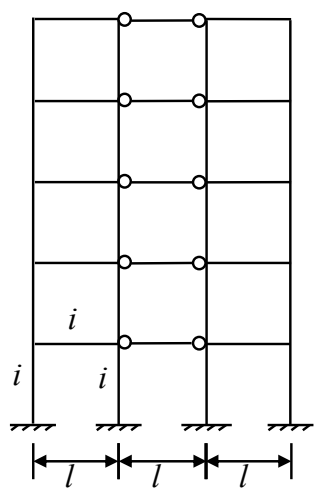

(d) Frame 4

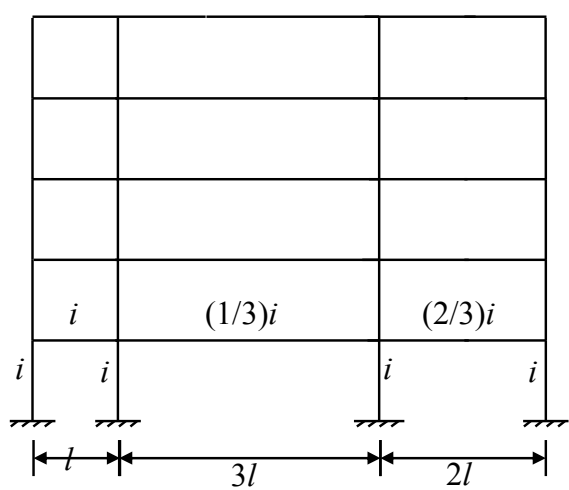

(b) Frame 2

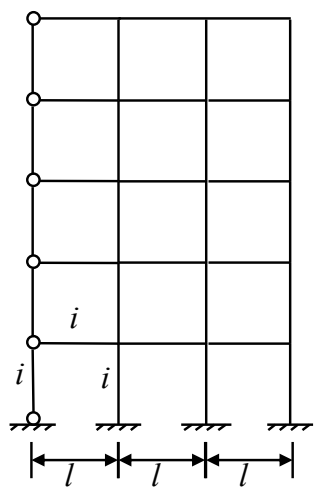

(e) Frame 5

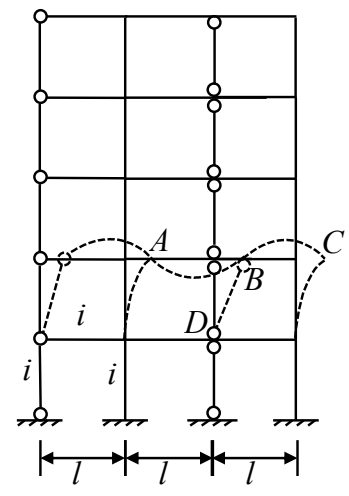

(f) Frame 6

Figure 6. Frame Type 4

A special consideration should be paid for side sway buckling of Frame model 6 in Frame Type 4 . For examples, the span flexural rigidity of beams like $A B$ and $B C$ as shown in Figure $6 \mathrm{f}$ should be modified. Due to the existence of leaning column $B D$, the rotations at the ends of beam $A B$ and $B C$ do not coincide with the Assumption 2 for unbraced frames stated in Section 2.3, but are analogous to the features of braced frame. This observation leads to a correction factor $1 / 3$ for span flexural rigidity of beams $A B$ and $B C$.

\subsubsection{Calculation of critical load using traditional approaches}

1. Calculating critical forces of all columns.

2. Obtaining critical story loads by using Eq. $27 \mathrm{a}$ or $27 \mathrm{~b}$.

3. The minimum of story critical forces is the critical load of the frame.

\subsubsection{Calculation of critical load by FEM software}

FEM solutions are obtained by the buckling analysis of ABAQUS software.

\subsubsection{The definition of errors}

Setting $P_{\mathrm{cr}}^{\mathrm{FEM}}, P_{\mathrm{cr}}^{\mathrm{M}}$ and $P_{\mathrm{cr}}^{\mathrm{T}}$ are critical load of the frame calculated by FEM, proposed effective length factor in modified approaches, and traditional approaches respectively. Errors of modified approaches and traditional approaches are defined as 


$$
\begin{aligned}
& \varepsilon^{\mathrm{M}}=\frac{P_{\mathrm{cr}}^{\mathrm{FEM}}-P_{\mathrm{cr}}^{\mathrm{M}}}{P_{\mathrm{cr}}^{\mathrm{FEM}}} \times 100 \% \\
& \varepsilon^{\mathrm{T}}=\frac{P_{\mathrm{cr}}^{\mathrm{FEM}}-P_{\mathrm{cr}}^{\mathrm{T}}}{P_{\mathrm{cr}}^{\mathrm{FEM}}} \times 100 \%
\end{aligned}
$$

\subsection{Numerical Results}

Comparison for Frame Type 1 4 can be seen from Table 2 5. The data in brackets in Table 2 4 are those corresponding to 8-span frame models, and non-bracket data are those of 3-span frame models.

Shown in Table 2, errors of modified approaches are significantly smaller than that of traditional approaches. For braced buckling, the maximal error of modified approaches is $7.4 \%$, however errors of traditional approaches hover around 21\% (for 3-span frames) and 15\% (for 8-span frames). For unbraced buckling, except for the results of 3-span with 3-story frame, the maximal error of modified approaches is $7.9 \%$, however errors of traditional approaches hover around $11 \%$. Besides, when the number of story is bigger than $3 \sim 5$, the absolute values of errors of modified approaches are within $5 \%$.

From Table 2, it is found that the prediction by modified approaches is not conservative when the number of stories is bigger than 15 20, but the absolute values of these errors are within 5\% which is acceptable.

Table 3 also shows that errors of modified approaches are obviously smaller than that of traditional approaches. Errors shown in Table 3 are mostly consistent with that in Table 2, which demonstrates the decrease of span flexural rigidity of beams has no significant effect on the accuracy of the two kinds of approaches. From Table 3, though modified approaches are not conservative when the number of story is bigger than 15 20, the absolute values of these errors are within 5\%.

Results of the two kinds of approaches are the same for the single story frames. It is because for the single story frame, inter-story interaction dose not exit, and modified approaches is consistent with traditional approaches.

From Table 4, although the two kinds of frames satisfied the key assumption of traditional approaches that stability functions of all columns are equal, errors of modified approaches are much smaller than that of traditional approaches. All the absolute values of errors of modified approaches in Table 4 are within 5\%.

By the results from Frame Type 4, it also exhibits the good accuracy of modified approaches compared with traditional approaches as shown in Table 5. The average error of modified approaches is $4.7 \%$, while the error of traditional approaches is $19 \%$. Modified approaches are not conservative for unbraced buckling of Frame model 5 and 6, while absolute values of the errors are within 5\% which is acceptable in practice. 
Table 2. Comparison of Critical Loads for Frames of Type 1

\begin{tabular}{|c|c|c|c|c|c|c|c|}
\hline \multirow[b]{2}{*}{$\begin{array}{l}\text { Buckling } \\
\text { mode }\end{array}$} & \multirow{2}{*}{$\begin{array}{c}\text { Number } \\
\text { of } \\
\text { spans }\end{array}$} & \multirow{2}{*}{$\begin{array}{c}\text { Number } \\
\text { of } \\
\text { stories }\end{array}$} & \multicolumn{3}{|c|}{ Critical load of the frame $(\times i / l)$} & \multicolumn{2}{|c|}{ Error of critical load (\%) } \\
\hline & & & FEM & $\begin{array}{c}\text { Modified } \\
\text { approaches }\end{array}$ & $\begin{array}{l}\text { Traditional } \\
\text { approaches }\end{array}$ & $\begin{array}{c}\text { Modified } \\
\text { approaches }\end{array}$ & $\begin{array}{l}\text { Traditional } \\
\text { approaches }\end{array}$ \\
\hline \multirow{8}{*}{$\begin{array}{c}\text { Braced } \\
\text { buckling }\end{array}$} & \multirow{8}{*}{$\begin{array}{c}3 \\
(8)\end{array}$} & 1 & $\begin{array}{c}29.837 \\
(28.687) \\
\end{array}$ & 28.573 & 28.573 & $\begin{array}{c}4.2 \\
(0.4)\end{array}$ & $\begin{array}{c}4.2 \\
(0.4)\end{array}$ \\
\hline & & 3 & $\begin{array}{c}9.5757 \\
(9.1404) \\
\end{array}$ & 8.9466 & 8.1575 & $\begin{array}{c}6.6 \\
(2.1) \\
\end{array}$ & $\begin{array}{c}15 \\
(11)\end{array}$ \\
\hline & & 5 & $\begin{array}{c}5.2370 \\
(4.9584) \\
\end{array}$ & 4.8474 & 4.0788 & $\begin{array}{c}7.4 \\
(2.2) \\
\end{array}$ & $\begin{array}{c}22 \\
(18)\end{array}$ \\
\hline & & 10 & $\begin{array}{c}2.3323 \\
(2.1914) \\
\end{array}$ & 2.1806 & 1.8128 & $\begin{array}{c}6.5 \\
(0.5) \\
\end{array}$ & $\begin{array}{c}22 \\
(17)\end{array}$ \\
\hline & & 15 & $\begin{array}{c}1.4774 \\
(1.3809)\end{array}$ & 1.3984 & 1.1654 & $\begin{array}{c}5.3 \\
(-1.3)\end{array}$ & $\begin{array}{c}21 \\
(16)\end{array}$ \\
\hline & & 20 & $\begin{array}{c}1.0780 \\
(1.0021) \\
\end{array}$ & 1.0282 & 0.8587 & $\begin{array}{c}4.6 \\
(-2.6) \\
\end{array}$ & $\begin{array}{c}20 \\
(14)\end{array}$ \\
\hline & & 25 & $\begin{array}{c}0.8487 \\
(0.7843) \\
\end{array}$ & 0.8076 & 0.6798 & $\begin{array}{c}4.8 \\
(-3.0) \\
\end{array}$ & $\begin{array}{c}20 \\
(13)\end{array}$ \\
\hline & & 30 & $\begin{array}{c}0.7007 \\
(0.6434) \\
\end{array}$ & 0.6639 & 0.5626 & $\begin{array}{c}5.3 \\
(-3.2) \\
\end{array}$ & $\begin{array}{c}20 \\
(13) \\
\end{array}$ \\
\hline \multirow{16}{*}{$\begin{array}{l}\text { Unbraced } \\
\text { buckling }\end{array}$} & \multirow{8}{*}{3} & 1 & 10.395 & 7.9725 & 7.9725 & 23 & 23 \\
\hline & & 3 & 3.2137 & 2.7909 & 2.9653 & 13 & 7.7 \\
\hline & & 5 & 1.7735 & 1.6336 & 1.5577 & 7.9 & 12 \\
\hline & & 10 & 0.7972 & 0.7777 & 0.6923 & 2.4 & 13 \\
\hline & & 15 & 0.5059 & 0.5034 & 0.4450 & 0.5 & 12 \\
\hline & & 20 & 0.3685 & 0.3709 & 0.3279 & -0.6 & 11 \\
\hline & & 25 & 0.2891 & 0.2932 & 0.2596 & -1.4 & 10 \\
\hline & & 30 & 0.2376 & 0.2415 & 0.2148 & -1.7 & 9.6 \\
\hline & \multirow{8}{*}{8} & 1 & 9.1651 & 8.1842 & 8.1842 & 11 & 11 \\
\hline & & 3 & 2.8838 & 2.7219 & 2.6318 & 5.6 & 8.7 \\
\hline & & 5 & 1.6162 & 1.5586 & 1.4449 & 3.6 & 11 \\
\hline & & 10 & 0.7353 & 0.7250 & 0.6422 & 1.4 & 13 \\
\hline & & 15 & 0.4686 & 0.4678 & 0.4128 & 0.2 & 12 \\
\hline & & 20 & 0.3421 & 0.3446 & 0.3042 & -0.7 & 11 \\
\hline & & 25 & 0.2688 & 0.2726 & 0.2408 & -1.4 & 10 \\
\hline & & 30 & 0.2210 & 0.2255 & 0.1993 & -2.0 & 9.8 \\
\hline
\end{tabular}


Table 3. Comparison of Critical Loads for Frames of Type 2

\begin{tabular}{|c|c|c|c|c|c|c|c|}
\hline \multirow[b]{2}{*}{$\begin{array}{l}\text { Buckling } \\
\text { mode }\end{array}$} & \multirow{2}{*}{$\begin{array}{c}\text { Number } \\
\text { of } \\
\text { spans }\end{array}$} & \multirow{2}{*}{$\begin{array}{c}\text { Number } \\
\text { of } \\
\text { stories }\end{array}$} & \multicolumn{3}{|c|}{ Critical load of the frame $(\times i / l)$} & \multicolumn{2}{|c|}{ Error of critical load (\%) } \\
\hline & & & FEM & $\begin{array}{c}\text { Modified } \\
\text { approaches }\end{array}$ & \begin{tabular}{|l|} 
Traditional \\
approaches
\end{tabular} & $\begin{array}{c}\text { Modified } \\
\text { approaches }\end{array}$ & $\begin{array}{r}\text { Traditional } \\
\text { approaches }\end{array}$ \\
\hline \multirow{8}{*}{$\begin{array}{c}\text { Braced } \\
\text { buckling }\end{array}$} & \multirow{8}{*}{$\begin{array}{c}3 \\
(8)\end{array}$} & 1 & $\begin{array}{c}28.716 \\
(27.553)\end{array}$ & 27.524 & 27.524 & $\begin{array}{c}4.2 \\
(0.1)\end{array}$ & $\begin{array}{c}4.2 \\
(0.1)\end{array}$ \\
\hline & & 3 & $\begin{array}{c}9.1750 \\
(8.7529)\end{array}$ & 8.5694 & 7.6174 & $\begin{array}{c}6.6 \\
(2.1)\end{array}$ & $\begin{array}{c}17 \\
(13)\end{array}$ \\
\hline & & 5 & $\begin{array}{c}4.9759 \\
(4.7113) \\
\end{array}$ & 4.6166 & 3.8087 & $\begin{array}{c}7.2 \\
(2.0) \\
\end{array}$ & $\begin{array}{c}23 \\
(19) \\
\end{array}$ \\
\hline & & 10 & $\begin{array}{c}2.1983 \\
(2.0659)\end{array}$ & 2.0694 & 1.6928 & $\begin{array}{c}5.9 \\
(-0.2)\end{array}$ & $\begin{array}{c}23 \\
(18)\end{array}$ \\
\hline & & 15 & $\begin{array}{c}1.3879 \\
(1.2979)\end{array}$ & 1.3261 & 1.0882 & $\begin{array}{c}4.5 \\
(-1.4)\end{array}$ & $\begin{array}{c}22 \\
(16)\end{array}$ \\
\hline & & 20 & $\begin{array}{c}1.0105 \\
(0.9402)\end{array}$ & 0.9722 & 0.8018 & $\begin{array}{c}3.8 \\
(-3.4) \\
\end{array}$ & $\begin{array}{c}21 \\
(15) \\
\end{array}$ \\
\hline & & 25 & $\begin{array}{c}0.7943 \\
(0.7350) \\
\end{array}$ & 0.7619 & 0.6348 & $\begin{array}{c}4.1 \\
(-3.7)\end{array}$ & $\begin{array}{c}20 \\
(14)\end{array}$ \\
\hline & & 30 & $\begin{array}{c}0.6549 \\
(0.6025) \\
\end{array}$ & 0.6263 & 0.5253 & $\begin{array}{c}4.4 \\
(-4.0) \\
\end{array}$ & $\begin{array}{c}20 \\
(13)\end{array}$ \\
\hline \multirow{16}{*}{$\begin{array}{l}\text { Unbraced } \\
\text { buckling }\end{array}$} & \multirow{8}{*}{3} & 1 & 9.9414 & 7.6489 & 7.6489 & 23 & 23 \\
\hline & & 3 & 2.9887 & 2.6699 & 2.7667 & 11 & 7.4 \\
\hline & & 5 & 1.6221 & 1.5364 & 1.3834 & 5.3 & 15 \\
\hline & & 10 & 0.7197 & 0.7163 & 0.6148 & 0.5 & 15 \\
\hline & & 15 & 0.4545 & 0.4616 & 0.3952 & -1.6 & 13 \\
\hline & & 20 & 0.3303 & 0.3398 & 0.2912 & -2.9 & 12 \\
\hline & & 25 & 0.2587 & 0.2686 & 0.2306 & -3.8 & 11 \\
\hline & & 30 & 0.2123 & 0.2212 & 0.1908 & -4.2 & 10 \\
\hline & \multirow{8}{*}{8} & 1 & 8.8111 & 7.8803 & 7.8803 & 11 & 11 \\
\hline & & 3 & 2.7053 & 2.5801 & 2.4850 & 4.6 & 8.1 \\
\hline & & 5 & 1.4907 & 1.4506 & 1.2947 & 2.7 & 13 \\
\hline & & 10 & 0.6692 & 0.6663 & 0.5754 & 0.4 & 14 \\
\hline & & 15 & 0.4245 & 0.4290 & 0.3699 & -1.1 & 13 \\
\hline & & 20 & 0.3091 & 0.3159 & 0.2726 & -2.2 & 12 \\
\hline & & 25 & 0.2425 & 0.2498 & 0.2158 & -3.0 & 11 \\
\hline & & 30 & 0.1992 & 0.2066 & 0.1786 & -3.7 & 10 \\
\hline
\end{tabular}


Table 4. Comparison of Critical Loads for Frames of Type 3

\begin{tabular}{|c|c|c|c|c|c|c|}
\hline \multirow{2}{*}{$\begin{array}{c}\text { Buckling } \\
\text { mode }\end{array}$} & \multirow{2}{*}{$\begin{array}{c}\text { Number } \\
\text { of } \\
\text { spans }\end{array}$} & \multicolumn{2}{|c|}{ Critical load of the frame $(\times i / l)$} & \multicolumn{2}{|c|}{ Error of critical load (\%) } \\
\cline { 3 - 7 } & FEM & $\begin{array}{c}\text { Modified } \\
\text { approaches }\end{array}$ & $\begin{array}{c}\text { Traditional } \\
\text { approaches }\end{array}$ & $\begin{array}{c}\text { Modified } \\
\text { approaches }\end{array}$ & $\begin{array}{c}\text { Traditional } \\
\text { approaches }\end{array}$ \\
\hline $\begin{array}{c}\text { Braced } \\
\text { buckling }\end{array}$ & $\begin{array}{c}3 \\
(8)\end{array}$ & $\begin{array}{c}1.5499 \\
(1.5864)\end{array}$ & 1.5961 & 1.3434 & $\begin{array}{c}-3.0 \\
(-0.6)\end{array}$ & $\begin{array}{c}13 \\
(15)\end{array}$ \\
\hline $\begin{array}{c}\text { Unbraced } \\
\text { buckling }\end{array}$ & 3 & 0.5574 & 0.5670 & 0.5137 & -1.7 & 7.8 \\
\cline { 2 - 7 } & 8 & 0.5061 & 0.5232 & 0.4673 & -3.4 & 7.7 \\
\hline
\end{tabular}

Table 5. Comparison of Critical Loads for Frames of Type 4

\begin{tabular}{|c|c|c|c|c|c|c|c|}
\hline \multirow[b]{2}{*}{$\begin{array}{l}\text { Buckling } \\
\text { mode }\end{array}$} & \multirow{2}{*}{$\begin{array}{c}\text { Number } \\
\text { of } \\
\text { frame }\end{array}$} & \multirow{2}{*}{$\begin{array}{c}\text { Feature } \\
\text { of } \\
\text { frame }\end{array}$} & \multicolumn{3}{|c|}{ Critical load of the frame $(\times i / l)$} & \multicolumn{2}{|c|}{ Error of critical load (\%) } \\
\hline & & & FEM & $\begin{array}{c}\text { Modified } \\
\text { approaches }\end{array}$ & $\begin{array}{l}\text { Traditional } \\
\text { approaches }\end{array}$ & $\begin{array}{c}\text { Modified } \\
\text { approaches }\end{array}$ & $\begin{array}{l}\text { Traditional } \\
\text { approaches }\end{array}$ \\
\hline \multirow{6}{*}{$\begin{array}{c}\text { Braced } \\
\text { buckling }\end{array}$} & 1 & \multirow{2}{*}{$\begin{array}{c}\text { Unequal } \\
\text { spans }\end{array}$} & 4.8911 & 4.5579 & 3.6157 & 6.8 & 26 \\
\hline & 2 & & 4.5352 & 4.2382 & 3.2227 & 6.5 & 29 \\
\hline & 3 & \multirow{2}{*}{$\begin{array}{c}\text { Hinged } \\
\text { conditions }\end{array}$} & 5.1982 & 4.9298 & 4.0788 & 5.2 & 22 \\
\hline & 4 & & 4.6960 & 4.3490 & 3.3584 & 7.4 & 28 \\
\hline & 5 & \multirow{2}{*}{$\begin{array}{l}\text { Leaning } \\
\text { columns }\end{array}$} & 3.9548 & 3.9478 & 3.9478 & 0.2 & 0.2 \\
\hline & 6 & & 1.9809 & 1.9739 & 1.9739 & 0.4 & 0.4 \\
\hline \multirow{6}{*}{$\begin{array}{l}\text { Unbraced } \\
\text { buckling }\end{array}$} & 1 & \multirow{2}{*}{$\begin{array}{c}\text { Unequal } \\
\text { spans }\end{array}$} & 1.6402 & 1.5282 & 1.3931 & 8.4 & 15 \\
\hline & 2 & & 1.4385 & 1.3562 & 1.1816 & 5.7 & 22 \\
\hline & 3 & \multirow{2}{*}{$\begin{array}{c}\text { Hinged } \\
\text { conditions }\end{array}$} & 1.4321 & 1.4082 & 1.1795 & 1.7 & 18 \\
\hline & 4 & & 1.5361 & 1.4012 & 1.2790 & 8.8 & 17 \\
\hline & 5 & \multirow{2}{*}{$\begin{array}{l}\text { Leaning } \\
\text { columns }\end{array}$} & 1.3644 & 1.4082 & 1.1795 & -3.2 & 14 \\
\hline & 6 & & 0.6725 & 0.6846 & 0.4308 & -1.8 & 36 \\
\hline
\end{tabular}

\section{CONCLUSIONS}

Referring to the traditional approaches, this paper proposed modified approaches to calculate effective length factor of frame columns. Computing results show that the modified approaches guarantee significantly higher accuracy than traditional approaches in general, and the absolute values of errors of modified approaches are within 5\% in most computed frame models. Modified approaches are more rational than traditional approaches. Besides, approximate formulas for effective length factor based on modified approaches are explicit analysis expressions which are easy to apply.

It also should be pointed out that iteration is needless in engineering application for modified approaches. Based on actual loads of the frame, critical story loads can be obtained by using Eqs. 12 or 24 . By comparing critical and actual story loads, the stability of the frame could be estimated.

Though effective length method is easily used in design process, it mainly applies to the determination of elastic critical loads of the frame structures. For complex and irregular structures like domes whose second order effects are significant, advanced analysis is required. 


\section{REFERENCES}

[1] American Institute of Steel Construction (AISC), "Specification for Structural Steel Buildings", ANSI/AISC 360-10, Chicago, 2010.

[2] Standards Australia Committee (SAC) BD/1, Steel Structures, "AS4100-1998, Australian Standard-Steel Structures", Standards Australia, New South Wales, 1998.

[3] GB50017-2003, "Code for Design of Steel Structures", Ministry of Construction, Architecture and Building Press, Beijing, 2003. (in Chinese)

[4] Kuhn, G. and Lundgren, H. R., "An Appraisal of the Effective Length Alignment Charts", International Colloquium on Stability of Structures under Static and Dynamic Loads, ASCE, New York, 1977, pp. 212-242.

[5] Chen, W.F. and Lui, E.M., "Structural Stability-Theory and Implementation”, Elsevier, New York, 1987.

[6] Bridge, R.Q. and Fraser, D.J., "Improved G-factor Method for Evaluating Effective Lengths of Columns", Journal of Structural Engineering, 1987, Vol. 113, No. 6, pp. 1341-1356.

[7] Essa, H.S., "Stability of Columns in Unbraced Frames", Journal of Structural Engineering, 1997, Vol. 123, No. 7, pp. 952-957.

[8] Kishi, N., Chen, W.F. and Goto, Y., "Effective Length Factor of Columns in Semirigid and Unbraced Frames", Journal of Structural Engineering, 1997, Vol. 123, No. 3, pp. 313-320.

[9] Kishi, N., Chen, W.F., Goto, Y. and Komuro, M., "Effective Length Factor of Columns in Flexibly Jointed and Unbraced Frames", Journal of Constructional Steel Research, 1998, Vol. 47, No. 1-2, pp. 93-118.

[10] Tong, G.S. and Wang, J.P., "Column Effective Lengths Considering Inter-story and Inter-column Interactions in Sway-permitted Frames", Journal of Constructional Steel Research, 2006, Vol. 62, No. 5, pp. 413-423.

[11] Yura, J.A., "The Effective Length of Columns in Unbraced Frames", Engineering Journal, 1971, Vol. 8, No. 2, pp. 37-42.

[12] White, D.W. and Hajjar, J.F., "Buckling Models and Stability Design of Steel Frames: A Unified Approach", Journal of Constructional Steel Research, 1997, Vol. 42, No. 3, pp. 171-207.

[13] Xu, L. and Liu, Y., "Story Stability of Semi-braced Steel Frames", Journal of Constructional Steel Research, 2002, Vol. 58, No. 4, pp. 467-491.

[14] Choi, D.H. and Yoo, H., "Iterative System Buckling Analysis, Considering A Fictitious Axial Force to Determine Effective Length Factor for Multi-story Frames", Engineering Structures, 2009, Vol. 31, No. 2, pp. 560-570.

[15] Galambos, T.V. and Surovek, A.E., "Structural Stability of Steel: Concepts and Applications for Structural Engineers", John Wiley \& Sons, Inc., Hoboken, New Jersey, 2008.

[16] Commission des Regles C. M. 66, "Regles de calcul des constructions en acier", Eyrolles, Paris, 1966. (in French)

[17] Dumonteil, P., "Simple Equations for Effective Length Factors", Engineering Journal, 1992, Vol. 29, No. 3, pp. 111-115.

[18] Dumonteil, P., "Historical Note on K-factor Equations", Engineering Journal, 1999, Vol. 36, No. 2, pp. 102-103. 